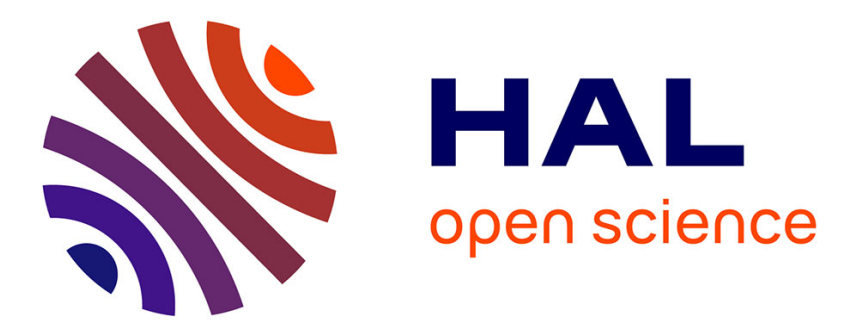

\title{
Performance modification of third-order optical nonlinearity of chalcogenide glasses by nanocrystallization
}

Y. Yang, T. Sun, C. Lin, S. Dai, Xianghua Zhang, W. Ji, F. Chen

\section{- To cite this version:}

Y. Yang, T. Sun, C. Lin, S. Dai, Xianghua Zhang, et al.. Performance modification of third-order optical nonlinearity of chalcogenide glasses by nanocrystallization. Ceramics International, 2019, 45 (15), pp.18767-18771. 10.1016/j.ceramint.2019.06.103 . hal-02181835

HAL Id: hal-02181835

https://hal-univ-rennes1.archives-ouvertes.fr/hal-02181835

Submitted on 17 Sep 2019

HAL is a multi-disciplinary open access archive for the deposit and dissemination of scientific research documents, whether they are published or not. The documents may come from teaching and research institutions in France or abroad, or from public or private research centers.
L'archive ouverte pluridisciplinaire HAL, est destinée au dépôt et à la diffusion de documents scientifiques de niveau recherche, publiés ou non, émanant des établissements d'enseignement et de recherche français ou étrangers, des laboratoires publics ou privés. 


\section{Performance modification of third-order optical nonlinearity of chalcogenide glasses by nanocrystallization}

Yinwei Yang ${ }^{1,2}$,Tingting Sun ${ }^{1,2}$, Changgui Lin ${ }^{1,2}$, Shixun Dai ${ }^{1,2}$, Xianghua Zhang

${ }^{3}$, Wei $\mathrm{Ji}^{4}$, Feifei Chen ${ }^{1,2, *}$

${ }^{1}$ Laboratory of Infrared Materials and Devices, The Research Institute of Advanced Technologies, Ningbo University, Ningbo 315211, China

${ }^{2}$ Key Laboratory of Photoelectric Detection Materials and Devices of Zhejiang Province, Ningbo University, Ningbo 315211, China

${ }^{3}$ Laboratory of Glasses and Ceramics, UMR 6226 CNRS-University of Rennes 1, Rennes Cedex 135042, France

${ }^{4}$ Department of Physics, National University of Singapore, 2 Science Drive 3, 117551, Singapore *Corresponding author. E-mail address: chenfeifei1@nbu.edu.cn.

Abstract: We demonstrate the modification of the third-order optical nonlinearity (TONL) of chalcogenide glasses (within the $\mathrm{GeS}_{2}-\mathrm{In}_{2} \mathrm{~S}_{3}-\mathrm{CsCl}$ ternary system) by nanocrystallization, i.e., by controlling the precipitation of nanocrystals (in pure $\operatorname{In}_{2} S_{3}$ phase) within the amorphous background. Compared with the parent glass, the resultant chalcogenide glass ceramics (ChGCs) have unchanged infrared transmittance but modifiable optical bandgap energy with treatment duration. Both nonlinear refraction coefficient and nonlinear absorption coefficient of the ChGCs are increased due to the appearance of $\operatorname{In}_{2} \mathrm{~S}_{3}$ nanocrystals. ChGCs subjected to heat treatment for 1.3-2 $\mathrm{h}$ are found to exhibit the optimum TONL performance.

Keywords: Nanomaterial; Nonlinear optical materials; Nonlinear optics; materials.

\section{Introduction}


Over the past decades, nonlinear optical devices particularly those based on third-order optical nonlinearity (TONL, $\left.\chi^{(3)}\right)[1]$ have received increased attention. Some of these devices include all-optical switching, super-continuum generation, and optical time division multiplexing. To fabricate devices with small size, low energy consumption, and fast processing speed, searching for nonlinear optical materials with large TONL is highly important[2-4]. Chalcogenide glasses (ChGs) have the largest TONL property among all optical-glass systems[5, 6]. They also possess high optical transmittance in the mid-infrared windows (i.e. $3 \sim 5$ and $8 \sim 14 \mu \mathrm{m}$ ). ChGs are amorphous semiconductors as well; they are compatible with both fiber-telecom and silicon technologies and are thus considered to be promising for the fabrication of both infrared and nonlinear photonic devices[7-11].

One of the fundamental $\mathrm{ChG}$ research hotspots is to optimize their properties by partial crystallization in a glass network[12-16]. ChG ceramics (ChGCs) comprising semiconductor crystals in nano- or micron-scale have been found to exhibit upgraded mechanical strength, rare-earth luminescence, and optical nonlinearity. For TONL property, enhanced nonlinear refractive $\left(n_{2}\right)$ behavior has first been reported by Lin in $\beta$-GeS 2 nanocrystallite (NC) embedded ChGCs[17]. Thus far, similar experimental results have been observed in ChGCs comprising $\mathrm{Ga}_{2} \mathrm{~S}_{3}[18]$, $\mathrm{AgCl}[19]$, and $\mathrm{GeS}_{2}$ [20] $\mathrm{NC}$, demonstrating that quantum effects from semiconductor NCs being a function of the crystallite type, size, and volume fraction have excellent versatility for the improvement of TONL performance of ChGCs. Our previous work[21] has reported the preparation of $\operatorname{In}_{2} \mathrm{~S}_{3}$ microcrystallites comprising transparent ChGCs, which we have anticipated to acquire higher TONL property than those embedded with $\mathrm{Ga}_{2} \mathrm{~S}_{3}$ and $\mathrm{GeS}_{2}$ crystallites because $\operatorname{In}_{2} \mathrm{~S}_{3}$ is a typical natural defective crystal with distinctive photoconductivity and broadband spectral response[22]. However, the 
TONL property of ChGCs has not been detailed due to the high scatting loss from $\mathrm{In}_{2} \mathrm{~S}_{3}$ crystallites having size in micro-scale.

In the present work, we investigate the TONL property of transparent $\mathrm{ChGCs}$ embedded with $\mathrm{In}_{2} \mathrm{~S}_{3}$ nanocrystallites (NCs) by using a femtosecond laser at a near-infrared wavelength of $800 \mathrm{~nm}$. Z-scan technique was performed to evaluate the nonlinear refractive index $\left(n_{2}\right)$ and nonlinear absorption coefficient $(\beta)$ of ChGCs as a function of treatment duration. The possibility of tailoring TONL performance was evaluated by figure of merit.

\section{Experimental}

Parent $\mathrm{ChG}$ with a molar composition of $65 \mathrm{GeS}_{2}-25 \mathrm{In}_{2} \mathrm{~S}_{3}-10 \mathrm{CsCl}$ (GIC) was selected and prepared from high purity polycrystalline, Ge (99.999\%), In (99.99\%), S (99.999\%), and $\mathrm{CsCl}(99.99 \%)$. The GIC ChGCs were prepared by heat treating the parent glass $30{ }^{\circ} \mathrm{C}$ above its transition temperature $\left(T_{\mathrm{g}}=346^{\circ} \mathrm{C}\right)$ for $1,1.3,2,3$ and 5 h. The corresponding ChGCs were denoted as GIC-1h, 1.3h, 2h, 3h, and 5h, respectively. The absorption and transmission spectra of samples ranging within 400$2500 \mathrm{~nm}$ were recorded using a UV-vis-NIR spectrophotometer (Lamda950, PerkinElmer, USA). Infrared transmission spectra ranging within 2.5-25 $\mu \mathrm{m}$ were obtained using a Fourier transform infrared spectrometer (Nicolet381, Nicolet, USA). The crystalline phases that precipitated in the ChGC samples were identified by X-ray diffraction (XRD; AXS D2 PHASER, Bruker, Germany) under 30 kV, 10 mA, Cu Ka radiation, and $0.02^{\circ}$ step width. Crystal morphology in the ChGCs was observed using a transmission electron microscopy (TEM) system (JEOL2100, JEOL, Japan).

Z-scan technique was used to study TONL properties including both nonlinear refraction and absorption behaviors of the GIC ChGCs at a near-infrared wavelength of $800 \mathrm{~nm}$. A Ti:sapphire laser (Mira 900-D, Coherent, USA) with a pulse width of 
$130 \mathrm{fs}$ and repetition frequency of $76 \mathrm{MHz}$ was used as laser source. The incident laser power detected by a highly sensitive power probe (Rkp-575, Laser Probe, USA) was set at $35 \pm 0.5 \mathrm{~mW}$ and focused on samples by using a $\mathrm{CaF}_{2}$ lens. The waist of laser beam $\left(\omega_{0}\right)$ at focus was estimated to be $18.5 \pm 1.5 \mu \mathrm{m}$, corresponding to a laser intensity $\left(I_{0}\right)$ of $7.98 \pm 1.21 \mathrm{GW} / \mathrm{cm}^{2}$. Notably, the pyroelectric power probe introduced approximately 5\% error because of thermal effects. Moreover, the scattering of the lens and glass samples added approximately $1.3 \%$ error. Thus, the calculated results of TONL parameters had approximately $20 \%$ error, which is within acceptable limits. The above measurements were conducted at room temperature.

\section{Results and discussion}

Figure 1 presents the full-band transmission spectra and a photograph of the GIC parent glass and ChGCs. The heat-treatment process caused a color change of the parent glass, but the infrared transmission window cutoff at $12 \mu \mathrm{m}$ remained unchanged for the GIC ChGCs, indicating that crystallization in the ChGC samples were below micronscale and the crystallites were homogeneously distributed in the GIC glass matrix.

To confirm the precipitation of $\operatorname{In}_{2} \mathrm{~S}_{3}$ crystallites in ChGCs, both parent glass and ChGC samples were ground to powder and subjected to XRD measurements. The XRD patterns shown in Fig. 2(a) indicated that GIC-2h showed a noticeable diffraction peak at $47.71^{\circ}$ above the amorphous background and its intensity grew with heat treatment. When the treatment duration reached $5 \mathrm{~h}$, another three diffraction peaks at $27.44^{\circ}, 33.24^{\circ}$, and $43.62^{\circ}$ were clearly observed in the XRD pattern of GIC-5h, which can be identified as the formation of $\beta-\operatorname{In}_{2} \mathrm{~S}_{3}$ (PDF No. 84-1385) crystallites according to the reference given at the bottom of Fig. 2(a). Notably, the diffraction intensity of the $\beta$ - $\operatorname{In}_{2} \mathrm{~S}_{3}$ crystal phase was much weaker than 
the amorphous background, meaning that the crystalline fraction was small in the ChGCs. For GIC-5h, it was below $3 \%$.

The TEM and high-resolution TEM (HRTEM) images of $\beta$ - $\operatorname{In}_{2} \mathrm{~S}_{3}$ crystallites in sample GIC-5h are presented in Figs. 2(b) and 2(c), respectively. According to the TEM image in Fig. 2(b), the average size of the crystallites with distinct lattice fringes is estimated to be $8.6 \mathrm{~nm}$, and the lattice space of 0.27 and $0.20 \mathrm{~nm}$ as shown in Fig. 2(c) confirmed the presence of the $\left(\begin{array}{lll}4 & 0 & 0\end{array}\right)$ and $\left(\begin{array}{lll}5 & 1 & 1\end{array}\right)$ crystallographic planes of $\beta-\operatorname{In}_{2} \mathrm{~S}_{3}$ crystals. Thus, crystallization in the GIC ChGCs can be defined as nanoscale, so it has no significant influence on the optical transmittance of the ChGCs in the infrared region.

The absorption spectra in Fig. 2(d) showed evident red shifting of the fundamental absorption edge when heat treatment was prolonged, which resulted in the color change of the GIC ChGCs. The optical bandgap energy $\left(E_{\mathrm{g}}\right)$ can be calculated from the location of the fundamental absorption edge by assuming that the linear absorption coefficient $\left(\alpha_{0}\right)$ is related to $E_{\mathrm{g}}$ as $\alpha_{0}{ }^{2}=\mathrm{B}\left(\mathrm{h} v-E_{\mathrm{g}}\right)[23]$, where $\mathrm{h} v$ is the incident photon energy and B is a constant. According to the calculation results given in Table 1, the shifting of the fundamental absorption edge to a longer wavelength can be numerically represented by the decrease in $E_{\mathrm{g}}$ as a result of the deposition of $\operatorname{In}_{2} \mathrm{~S}_{3}$ crystals with $E_{\mathrm{g}}$ of $1.94 \mathrm{eV}[24]$ within the parent glass $\left(E_{\mathrm{g}}=2.66\right.$ $\mathrm{eV})$. Furthermore, by overlapping the fundamental absorption edge of all samples, an increasing onset of the absorption tail (known as the Urbach band[25,26] illustrated in the inset of Fig. 2(d)) can be observed. This phenomenon was intensified by prolonging the heat treatment, which can be recognized as the direct evidence of the increasing number of $\operatorname{In}_{2} \mathrm{~S}_{3} \mathrm{NCs}[21,27]$ in the GIC glass network. Fig. 3 shows a relatively linear dependence of $E_{\mathrm{g}}$ on treatment duration $(<5 \mathrm{~h})$, indicating linear 
growth of the number of $\operatorname{In}_{2} \mathrm{~S}_{3}$ NCs. However, the $E_{\mathrm{g}}$ value of GIC-5h was far above the one excepted from linear fitting, which was due to the loss of size confinement as a result of the agglomeration of $\operatorname{In}_{2} \mathrm{~S}_{3} \mathrm{NCs}$ that can be observed on the top part of the TEM image shown in Fig. 2(b).

The TONL properties of the GIC parent glass and ChGCs were investigated by closed-aperture (CA) and open-aperture (OA) Z-scan method at a near-infrared wavelength of $800 \mathrm{~nm}$. The CA Z-scans shown in Fig. 4(a) indicated that all traces had a peak-following-valley configuration, meaning that the samples had a positive nonlinear refractive index $\left(n_{2}\right)$ at $800 \mathrm{~nm}$. Furthermore, the distance of transmittance between valley and peak $\left(\Delta T_{\mathrm{v}-\mathrm{p}}\right)$ in the CA Z-scans underwent obvious amplification upon heat treatment, demonstrating that the increase in $n_{2}$ resulted from the deposition of $\mathrm{In}_{2} \mathrm{~S}_{3}$ NCs. By fitting the CA Z-scans with the Gaussian decomposition method[28, 29], the $n_{2}$ values of the samples were estimated and are shown in Table 1. The variation tendency agreed with that of $\Delta T_{\mathrm{v}-\mathrm{p}}$, i.e., the maximum $n_{2}$ obtained from sample GIC-5h reached $14 \times 10^{-4} \mathrm{~cm}^{2} / \mathrm{GW}$, which was over three times that of the parent glass with $n_{2}$ of $3.81 \times 10^{-4} \mathrm{~cm}^{2} / \mathrm{GW}$. Besides, as the experimental data given in Table $1, n_{2}$ value of the present ChGCs is larger than those of ChG film $\left(\operatorname{Sn}_{1} \mathrm{As}_{20} \mathrm{~S}_{79}\right.$ in molar composition)[9], bulk $\mathrm{ChG}\left(\mathrm{Ga}_{8} \mathrm{Sb}_{32} \mathrm{~S}_{60}\right.$ in molar composition)[10] and $\alpha-\mathrm{Ga}_{2} \mathrm{~S}_{3}$ embedded ChGC ( $\mathrm{Ga}_{10} \mathrm{Ge}_{25} \mathrm{~S}_{65}$ in molar composition)[18] reported recently.

The OA Z-scans given in Fig. 4(b) illustrate the presence of a valley in the center of each trace, which can be attributed to reverse-saturated absorption. Given that the normalized photon energy $\left(\mathrm{h} v / E_{\mathrm{g}}\right.$, where $\mathrm{h} v=1.55 \mathrm{eV}$ is the incident photon energy at $800 \mathrm{~nm}$ ) of the samples between 0.6 and 0.7 were within the two-photon absorption region (TPA; $0.5<\mathrm{h} v / E_{\mathrm{g}}<1$ )[30], we can ascribe the nonlinear absorption behavior of the GIC parent glass and ChGCs at $800 \mathrm{~nm}$ to the TPA process. The corresponding 
TPA coefficient $(\beta)$ can be estimated by fitting the OA Z-scans using a TPA model. The calculation results are given in Table 1. Clearly, $\beta$ increased monotonously with prolonged treatment duration, consistent with the size variation of the valley in the OA Z-scans. The maximum $\beta$ was obtained from GIC-5h, and the value of 5.86 $\mathrm{cm} / \mathrm{GW}$ was over three times to that of the parent glass as well.

According to the well-established two-band theory[31], $E_{\mathrm{g}}$ is considered to be the primary factor that determines the TONL property of dielectric and semiconductor materials. Especially in the TPA region, the possibility of photon-induced electronic transitions from the valance band (VB) to the conduction band (CB) by means of TPA can be promoted due to the reduction in bandgap energy (namely $E_{\mathrm{g}}$ ) between VB and CB. Consequently, the enhanced electronic transitions caused stronger distortion of the electron orbits around the nuclei of the materials, giving rise to a larger nonlinear refraction $\left(n_{2}\right)$. However, the increase rate of $n_{2}$ against $E_{\mathrm{g}}{ }^{-1}$ was inconsistent with that of $\beta$, so evaluating TONL performance by figure of merit (FOM) was necessary. For $n_{2}$-based nonlinear devices, such as all-optical switching and supercontinuum generation, the corresponding FOMs can be calculated by the following equations[32]:

$$
\begin{aligned}
& T=\frac{\beta \lambda}{n_{2}}<1 \\
& W=\frac{n_{2} I_{0}}{\alpha_{0} \lambda}>1
\end{aligned}
$$

where $T$ and $W$ are FOMs that evaluate the trade-off between wavelength $(\lambda)$, optical absorption, and $n_{2} ; \alpha_{0}$ is the linear absorption coefficient; and $I_{0}$ is the peak power density of the laser. The calculated FOMs of the samples are presented in Table 1, which shows that all $T$ values satisfied the corresponding criterion. Thus, the GIC parent glass and ChGCs exhibited relatively weak TPA process at $800 \mathrm{~nm}$. 
Accordingly, we can expect an even lower or absent TPA at longer wavelengths, especially at a communication wavelength of $1.55 \mu \mathrm{m}$ in which the $\mathrm{h} v / E_{\mathrm{g}}$ values would be between 0.3 and 0.4 , far below the TPA edge at $\mathrm{h} v / E_{\mathrm{g}}=0.5$ [33]. For the second criterion, only two ChGC samples in the middle of the series satisfied $W>1$ when error was considered as a result of the presence of optical absorption from the Urbach tail at $800 \mathrm{~nm}$. Therefore, we also anticipated that the improvement in $W$ for the ChGCs can occur at longer wavelengths due to the reduction in linear absorption coefficient as illustrated in the absorption spectra.

Table 1 also implies that both FOMs had no evident dependence on heat-treatment duration, but both their optimal values can be obtained in samples GIC-1.3h and GIC-2h. This finding indicated that such short treatment duration was sufficient for the performance improvement of TONL property of the GIC ChGs. Indeed, as illustrated in Fig. 3, optimization of the TONL performance of GIC ChGCs primarily relied on the modification of the $E_{\mathrm{g}}$ value, which can be achieved by controlling the heat-treatment duration. Fig. 5 shows the relationship between $n_{2}$ and $\mathrm{h} v / E_{\mathrm{g}}$ for the present GIC glass and ChGCs, and it can be well fitted by Dinu's model[34] that describes the dispersion of nonresonant TONL. For sample GIC-5h, its maximum $n_{2}$ and $\beta$ values may have been due to its $h v / E_{\mathrm{g}}$ value of 0.7 , which has been theoretically proved as the characteristic peak values for the $n_{2}$ and $\beta$ of indirect-gap semiconductors[35]. When $\mathrm{h} v / E_{\mathrm{g}}$ exceeded $0.7, n_{2}$ and $\beta$ decreased and the rate of decrease of $n_{2}$ was much faster than that of $\beta$, leading to rapidly reduced TONL performance. Thus, maintaining the treatment duration within $5 \mathrm{~h}$ is theoretically correct to optimize TONL performance of the GIC ChGs.

\section{Conclusions}

We prepared $\beta$ - $\operatorname{In}_{2} \mathrm{~S}_{3}$ nanocrystal-embedded transparent ChGCs by fast heat 
treating a $65 \mathrm{GeS}_{2}-25 \mathrm{In}_{2} \mathrm{~S}_{3}-10 \mathrm{CsCl}$ (in molar percentage) ChG. After annealing the glass $30{ }^{\circ} \mathrm{C}$ above its transition temperature for $<5 \mathrm{~h}$, we observe evident shifting of the absorption edge toward a longer wavelength as a result of the appearance of $\beta$ - $\operatorname{In}_{2} \mathrm{~S}_{3}$ crystallites $<10 \mathrm{~nm}$ in size. By using femtosecond Z-scan method at a wavelength of $800 \mathrm{~nm}$, the nonlinear refraction index $\left(n_{2}\right)$ and two-photon absorption coefficient $(\beta)$ in the transparent ChGCs increase by over three times compared with those of the parent glass. The optimum third-order nonlinear performance is obtained from ChGCs treated between 1.3 and $2 \mathrm{~h}$, indicating the possibility to tune the nonlinear optical properties of ChGs through nanocrystallization.

\section{Funding}

This work was partially supported by National Natural Science Foundation of China (grant no. 61675106), Natural Science Foundation of Zhejiang Province (grant no. LY19F050005) and National Key Research and Development Program of China (grant no. 2016YFB0303803). It was also sponsored by K.C. Wong Magna Fund in Ningbo University.

\section{Acknowledgements}

We acknowledge Prof. Peiqing Zhang for operation of the femtosecond laser, Dr. Yaru Liang for operation of the TEM microscopy.

\section{References}

[1] G. Agrawal, "Applications of nonlinear fiber optics, SanDiego: Academic Press; (2008).

[2] D.N. Christodoulides, I.C. Khoo, G.J. Salamo, G.I. Stegeman, and E.W. Van Stryland, Nonlinear refraction and absorption: mechanisms and magnitudes, Adv. Opt. Photon., 2(1) (2010) 60-200.

[3] H. Zeng, Z. Liu, Q. Jiang, B, Li, C. Yang, Z. Shang, J. Ren, G, Chen, Large 
third-order optical nonlinearity of $\mathrm{ZnO}-\mathrm{Bi}_{2} \mathrm{O}_{3}-\mathrm{B}_{2} \mathrm{O}_{3}$ glass-ceramic containing $\mathrm{Bi}_{2} \mathrm{ZnB}_{2} \mathrm{O}_{7}$ nanocrystals, J. Eur. Ceram. Soc., 34(16) (2014) 4383-4388.

[4] S. Liu, G. Chen, Y. Huang, S. Lin, Y. Zhang, M. He, W. Xiang, X. Liang, Tunable fluorescence and optical nonlinearities of all inorganic colloidal cesium lead halide perovskite nanocrystals, J. Alloy. Compd., 721 (2017) 889-896.

[5] A. Zakery and S. R. Elliott, Optical nonlinearities in chalcogenide glasses and their applications, Heidelberg : Springer Berlin Heidelberg; (2007).

[6] J.L. Adam and X. Zhang, Chalcogenide Glasses: Preparation, Properties and Applications, Sawston, Cambridge: Woodhead Publishing Limited; (2013).

[7] B.J. Eggleton, B.Luther-Davies, and K. Richardson, Chalcogenide photonics, Nat. Photon., 5(3) (2011) 141-148.

[8] L. Li, H. Lin, S. Qiao, Y. Zou, S. Danto, K. Richardson, J. D. Musgraves, N. Lu, and J. Hu, Integrated flexible chalcogenide glass photonic devices, Nat. Photon., 8(8) (2014) 643-649.

[9] L.E. Zou, P.P. He, B.X. Chen, and M. Iso, Nonlinear optical properties of $\mathrm{As}_{20} \mathrm{~S}_{80}$ system chalcogenide glass using Z-scan and its strip waveguide under bandgap light using the self-phase modulation, AIP Adv., 7(2) (2017) 025003.

[10] A. Yang, M. Zhang, L. Lei, Y. Wang, B. Zhang, Z. Yang, and D. Tang, Ga-Sb-S chalcogenide glasses for mid-infrared applications, J. Am. Ceram. Soc., 99(1) (2015) 12-15.

[11] B.U. Sohn, M. Kang, J.W. Choi, A.M. Agarwal, K. Richardson, D.T.H. Tan, Observation of very high order multi-photon absorption in GeSbS chalcogenide glass, APL Photon., 4(3) (2019) 036102.

[12] C. Lin, C. Rüssel, and S. Dai, Chalcogenide glass-ceramics: Functional design and crystallization mechanism, Prog. Mater. Sci., 93 (2018) 1-44. 
[13] X. Lu, Z. Lai, J. Ren, L. Strizik, T. Wagner, Y. Du, G. Farrell, P. Wang, Distribution of $\mathrm{Tm}^{3+}$ and $\mathrm{Ni}^{2+}$ in chalcogenide glass ceramics containing $\mathrm{Ga}_{2} \mathrm{~S}_{3}$ nanocrystals: Influence on photoluminescence properties, J. Eur. Ceram. Soc., 39(7) (2019) 2580-2584.

[14] C. Goncalves , M. Kang B.-U. Sohn, G. Yin, J. Hu, D. Tan, K. Richardson, New candidate multicomponent chalcogenide glasses for supercontinuum generation, Appl. Sci. 8(11) (2018) 2082.

[15] Z. Gao, S. Guo, X. Lu, J. Orava, T. Wagner, L. Zhang, Y. Liu, Y. Liu, S. Sun, F. He, P. Yang, J. Ren, J. Yang, Controlling selective doping and energy transfer between transition metal and rare earth ions in nanostructured glassy solids, Adv. Opt. Mater., 6(13) (2018) 1701407.

[16] T. Sun, F. Chen, C. Lin, X. Xue, Y. Yang, S. Dai, X. Zhang, W. Ji, Local field effect influenced third-order optical nonlinearity of whole visible transparent chalcogenide glass ceramics, Ceram. Int., 45(8) (2019) 10840-10844.

[17] C. Lin, L. Calvez, L. Ying, F. Chen, B. Song, X. Shen, S. Dai, and X. Zhang, External influence on third-order optical nonlinearity of transparent chalcogenide glass-ceramics, Appl. Phys. A, 104(2) (2011) 615-620.

[18] F. Chen, S. Dai, C. Lin, Q. Yu, and Q. Zhang, Performance improvement of transparent germanium-gallium-sulfur glass ceramic by gold doping for third-order optical nonlinearities, Opt. Express, 21(21) (2013) 24847-24855.

[19] X. Shen, X. Fang, F. Chen, S. Dai, X. Wang, T. Xu, Q. Nie, Preparation and optical properties of glass ceramics based on $\mathrm{GeS}_{2}-\mathrm{Ga}_{2} \mathrm{~S}_{3}-\mathrm{AgCl}$ ternary system, $\mathrm{J}$. Chin. Ceram. Soc., 38(8) (2010) 1563-1567.

[20] X. Shen, F. Chen, X. Lv, S. Dai, X. Wang, W. Zhang, B. Song, T. Xu, Q. Nie, and C. Liu, Preparation and third-order optical nonlinearity of glass ceramics based 
on $\mathrm{GeS}_{2}-\mathrm{Ga}_{2} \mathrm{~S}_{3}-\mathrm{CsCl}$ pseudo-ternary system, J. Non-Cryst. Solids, 357(11) (2011) 2316-2319.

[21] Z. Li, C. Lin, Q. Nie, and S. Dai, Controlled crystallization of $\beta-\operatorname{In}_{2} S_{3}$ in $65 \mathrm{GeS}_{2} \cdot 25 \operatorname{In}_{2} \mathrm{~S}_{3} \cdot 10 \mathrm{CsCl}$ chalcohalide glass, Appl. Phys. A, 112(4) (2013) 939-946.

[22] W. Huang, L. Gan, H. Yang, N. Zhou, R. Wang, W. Wu, H. Li, Y. Ma, H. Zeng, and T. Zhai, Controlled synthesis of ultrathin $2 \mathrm{D} \beta-\mathrm{In}_{2} \mathrm{~S}_{3}$ with broadband photoresponse by chemical vapor deposition, Adv. Funct. Mater., 27(36) (2017) 1702448.

[23] M.M.A. Imran and O.A. Lafi, Glass transition kinetics and optical band gap in $\mathrm{Se}_{85-\mathrm{x}} \mathrm{Sb}_{15} \mathrm{Sn}_{\mathrm{x}}(\mathrm{x}=10,11,12.5$, and 13) chalcogenide glasses, Mater. Chem. Phys., 129(3) (2011) 1201-1206.

[24] C.-H. Ho, Growth and characterization of near-band-edge transitions in $\beta-\operatorname{In}_{2} \mathrm{~S}_{3}$ single crystals, J. Cryst. Growth, 312(19) (2010) 2718-2723.

[25] S.K.J. Al-Ani, C.A. Hogarth, and R.A. El-Malawany, A study of optical absorption in tellurite and tungsten-tellurite glasses, J. Mater. Sci., 20(2) (1985) $661-667$.

[26] K. Tanaka, "Structural phase transitions in chalcogenide glasses," Phys. Rev. B, 39(2) (1989) 1270-1279.

[27] A. Edgar, G.V.M. Williams, and J. Hamelin, Optical scattering in glass ceramics, Curr. Appl. Phys., 6(3) (2006) 355-358.

[28] M. Yin, H.P. Li, S.H. Tang, and W. Ji, Determination of nonlinear absorption and refraction by single Z-scan method, Appl. Phys. B-Lasers O, 70 (2000) 587-591.

[29] S. Chen, Z.. Liu, W. Zang, J.. Tian, W. Zhou, F. Song, and C. Zhang, Study on Z-scan characteristics for a large nonlinear phase shift, J. Opt. Soc. Am. B, 22(9) 
(2005) 1911-1916.

[30] F. Théberge, P. Mathieu, N. Thiré, J.F. Daigle, B.E. Schmidt, J. Fortin, R. Vallée, Y. Messaddeq, and F. Légaré, Mid-infrared nonlinear absorption in $\mathrm{As}_{2} \mathrm{~S}_{3}$ chalcogenide glass, Opt. Express, 24(21) (2016) 24600.

[31] C. Aversa, J. E. Sipe, M. Sheik-Bahae, and E.W. Van Stryland, Third-order optical nonlinearities in semiconductors: The two-band model, Phys. Rev. B, 50(24) (1994) 18073-18082.

[32] D. Marchese, M.D. Sario, A. Jha, A.K. Kar, and E.C. Smith, Highly nonlinear $\mathrm{GeS}_{2}$-based chalcohalide glass for all-optical twin-core-fiber switching, J. Opt. Soc. Am. B, 15(15) (1998) 2361-2370.

[33] K. Tanaka, Two-photon optical absorption in amorphous materials, J. Non-Cryst. Solids, 338-340 (2004) 534-538.

[34] M. Dinu, Dispersion of phonon-assisted nonresonant third-order nonlinearities, IEEE J. Quant. Electron., 39(11) (2003) 1498-1503.

[35] K. Tanaka, Nonlinear optics in glasses: How can we analyze?, J. Phys. Chem. Solids, 68(5-6) (2007) 896-900.

\section{Tables}

\section{Table 1 Optical band gap and TONL parameters of the GIC parent glass, ChGCs and other ChG materials reported in recent studies for comparison.}

\section{Figures}

Fig. 1 Full-band transmission spectra of GIC parent glass and ChGCs; inset is a photograph of polished samples.

Fig. 2 (a) XRD patterns of GIC parent glass, ChGCs, and the $\beta-\operatorname{In}_{2} \mathrm{~S}_{3}$ phase. (b) TEM image of 
$\beta$-In $\mathrm{S}_{3}$ crystallites in sample GIC-5h. (c) HRTEM image of $\beta$ - $\operatorname{In}_{2} \mathrm{~S}_{3}$ crystallites. (d) Absorption spectra of the GIC parent glass and ChGCs showing the shifting of the fundamental absorption edge; inset is the overlapping of absorption tails, i.e., the Urbach band.

Fig. 3 Optical bandgap energy $\left(E_{\mathrm{g}}\right)$ as a function of the treatment time; the solid line is linear fitting.

Fig. 4 (a) Closed-aperture (CA) Z-scan traces of the parent glass, GIC-1.3h, and GIC-5h. (b) The corresponding open-aperture $(\mathrm{OA}) \mathrm{Z}$-scan traces; the solid lines are theoretical fitting.

Fig. 5 Fitting of plot of $n_{2}$ vs. h $v / E_{\mathrm{g}}$ by using Dinu's model. 
Table 1 Optical band gap and TONL parameters of the GIC parent glass, ChGCs and other ChG materials reported in recent studies for comparison.

\begin{tabular}{cccccc}
\hline & $E_{\mathrm{g}}$ & $n_{2}$ & $\beta$ & $T$ & $W$ \\
Sample No. & $(\mathrm{eV})$ & $\begin{array}{c}\left(10^{-4}\right. \\
\pm 0.0\end{array}$ & $\begin{array}{c}\left.\mathrm{cm}^{2} / \mathrm{GW}\right) \\
(\mathrm{cm} / \mathrm{GW})\end{array}$ & \pm 40 & \pm 40 \\
& 1 & $\pm 20 \%$ & $\pm 20 \%$ & $\%$ & $\%$ \\
\hline Parent glass & 2.66 & 3.81 & 1.69 & 0.37 & 0.82 \\
\hline GIC-1h & 2.49 & 5.45 & 1.98 & 0.29 & 1.01 \\
\hline GIC-1.3h & 2.47 & 10.02 & 1.83 & 0.15 & 1.73 \\
\hline GIC-2h & 2.35 & 9.49 & 2.53 & 0.21 & 2.38 \\
\hline GIC-3h & 2.22 & 11.58 & 4.30 & 0.30 & 1.12 \\
\hline $\mathrm{GIC}^{2}$ h & 2.19 & 14.04 & 5.86 & 0.33 & 0.82 \\
\hline${ }^{*} \mathrm{Sn}_{1} \mathrm{As}_{20} \mathrm{~S}_{79} \mathrm{ChG} \mathrm{film}^{9}$ & 2.77 & 0.41 & 0.31 & 0.80 & - \\
\hline${ }^{*} \mathrm{Ga}_{8} \mathrm{Sb}_{32} \mathrm{~S}_{60}{ }^{10}$ & 2.06 & 1.24 & - & - & - \\
\hline${ }^{*} \alpha-\mathrm{Ga}_{2} \mathrm{~S}_{3}$ embedded & 2.83 & 2.40 & 0.95 & 0.32 & - \\
$\mathrm{ChGC}^{18}$ & & & & &
\end{tabular}

*Z-scan wavelength used in Ref. 9 and Ref. 10 are 1.064 and $1.55 \mu \mathrm{m}$, respectively.

${ }^{\#}$ The molar composition of the ChGC reported in Ref. 18 is $\mathrm{Ga}_{10} \mathrm{Ge}_{25} \mathrm{~S}_{65}$. 


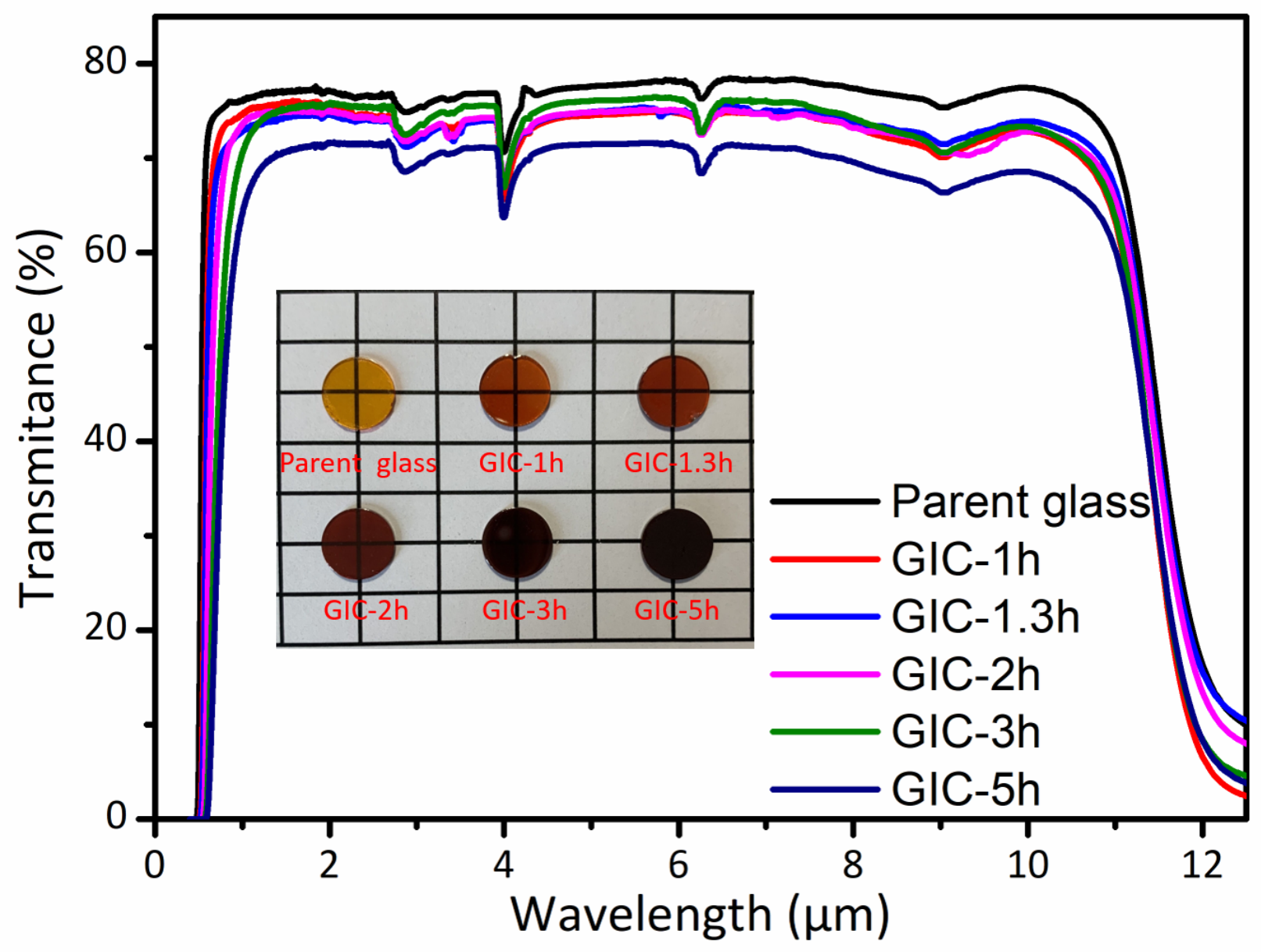




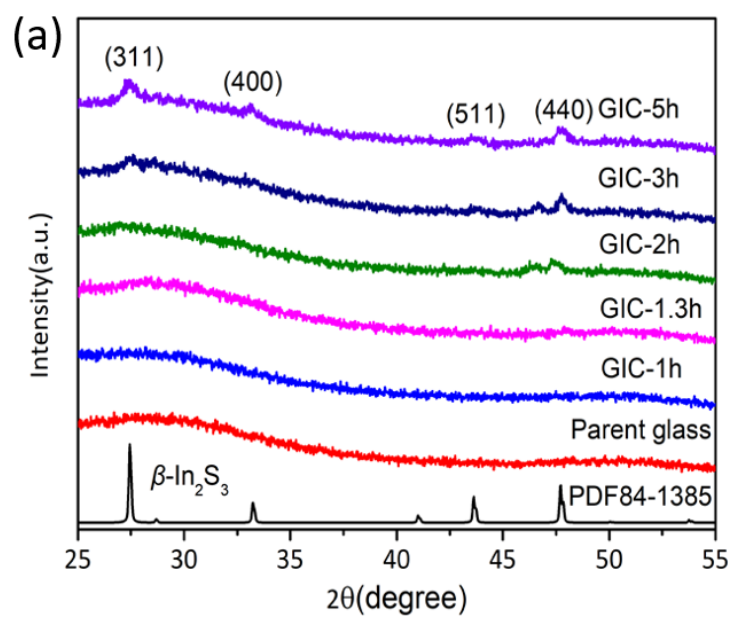

(b)

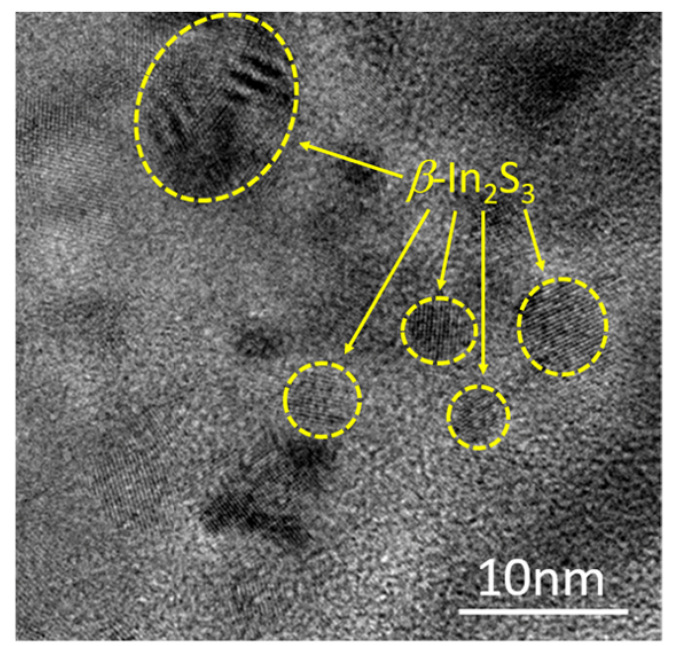

(c)
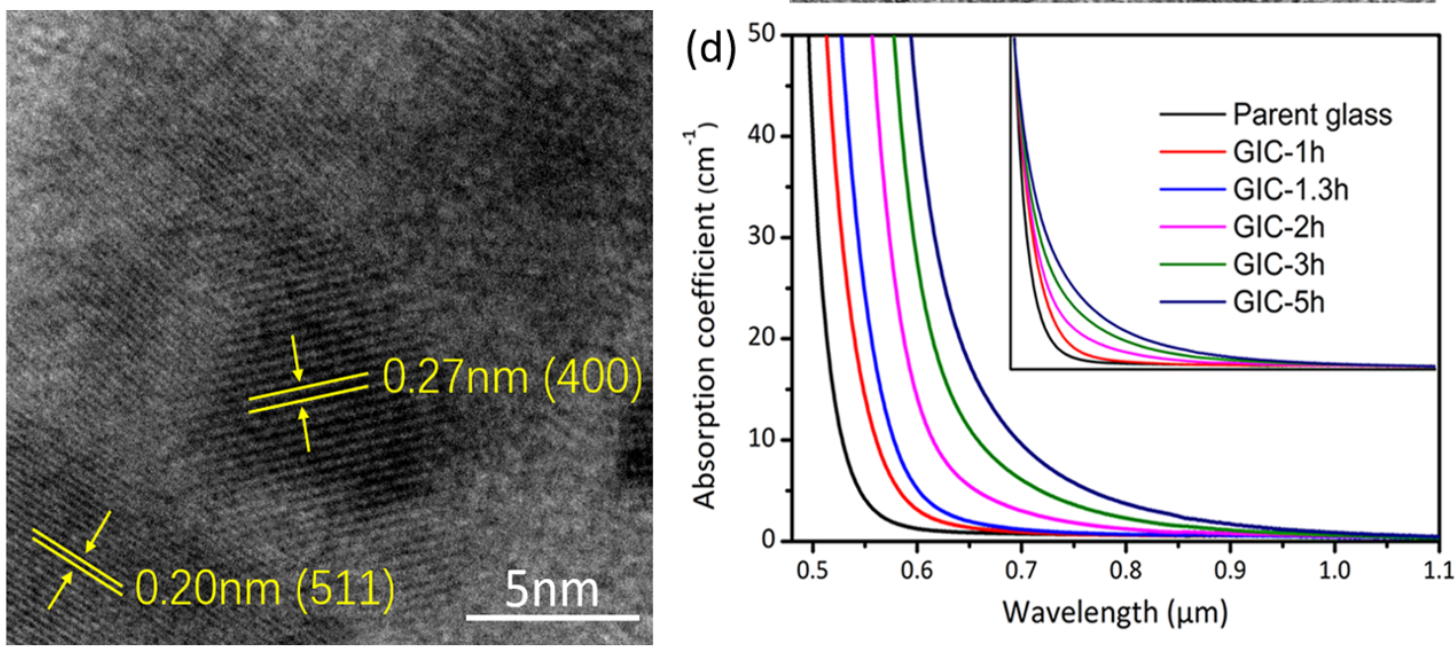


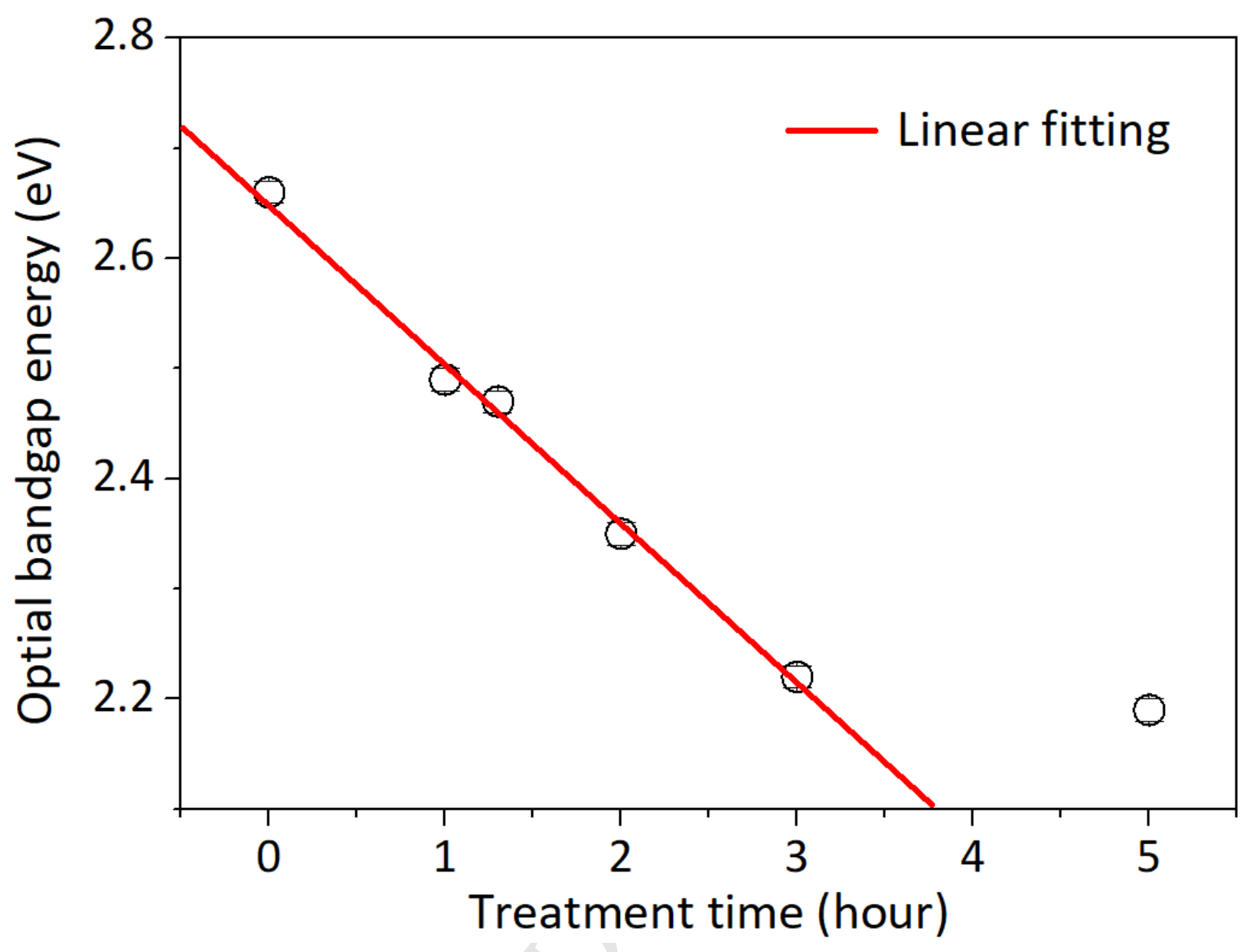



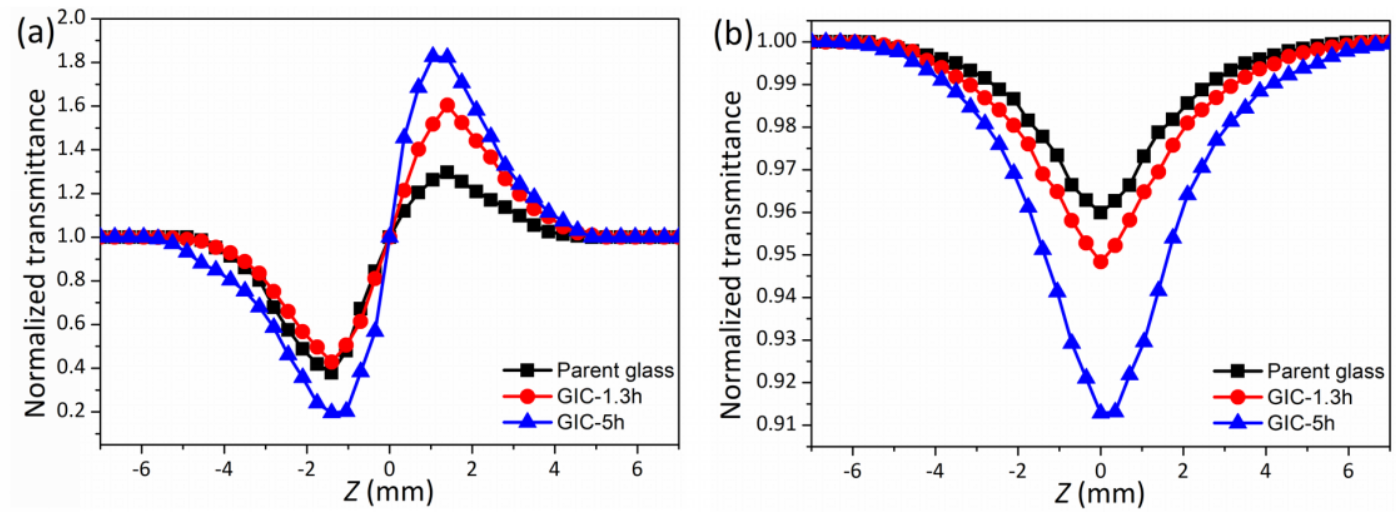


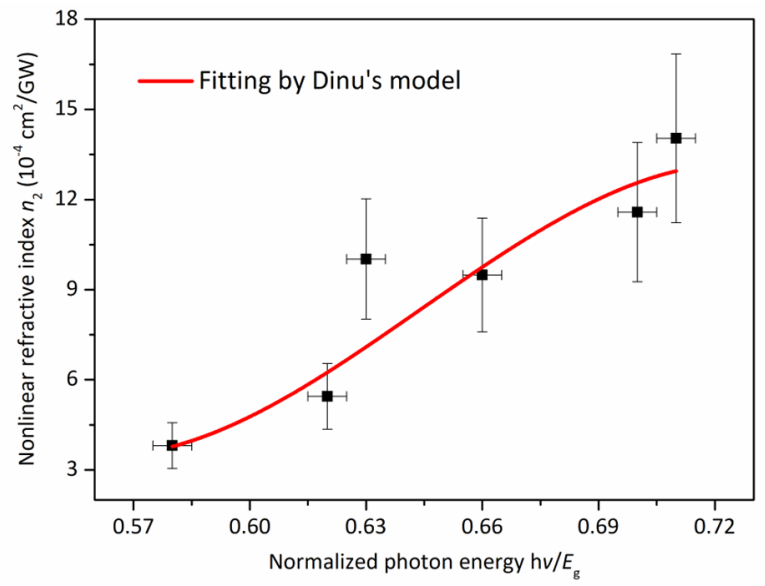

